\title{
Photoswitchable mixed valence
}

\author{
Oliver S. Wenger*a \\ Received (in $X X X, X X X)$ ) th $X X X X X X X X X 20 X X$, Accepted Xth $X X X X X X X X X 20 X X$ \\ DOI: $10.1039 / b 000000 x$
}

${ }_{5}$ For a molecular electronics technology to be fully serviceable, switching functions will be indispensable. Specifically, it will be desirable to control the conductivity of a given molecule using an external stimulus. Photoswitchable mixed valence systems are comprised of a reversibly photoisomerizable bridging unit connecting two redox-active moieties, and as such represent some of the most simple chemical systems in which switching of charge delocalization can be explored. As photoisomerizable

10 units, dithienylethenes have received much attention in the context of photoswitchable mixed valence, but there are also more exotic examples such as norbornadiene- and dimethyldihydropyrene-based switchable systems. As redox-active units responsible for the mixed valence phenomenon, both metal-containing as well as purely organic moieties have been employed. Typical investigations in this area involve the comparison of cyclic voltammograms and (near-infrared) optical absorption spectra of the two isomeric

15 forms of a given system. The magnitude of the comproportionation constant and evaluation of intervalence absorption bands using appropriate theoretical models yield information regarding the extent of charge delocalization in the two isomeric forms. In several of the compounds investigated so far, the light stimulus induces a substantial increase of charge delocalization, or in the terminology commonly used in mixed valence chemistry, a changeover from class I to class II or even class III behavior.

\section{${ }_{20}$ 1. Introduction}

Mixed valence species contain two chemically identical units that are formally in different oxidation states. ${ }^{1}$ These redox-active units may contain metals, ${ }^{2-4}$ or they may be entirely organic. ${ }^{5-6,60}$ Although there are exceptions to this rule, ${ }^{7}$ the two redox-active 25 centers typically differ in oxidation state formally by one unit, and consequently there is usually one unpaired electron in mixed valence systems. ${ }^{1-6}$ This odd electron may be localized entirely on one of the two redox centers, or it may be partially or even fully delocalized between them. Depending on which of the three 30 possible scenarios is encountered, the mixed valence species is categorized as a class I, class II or class III system. ${ }^{4-5,8}$ To which class a newly synthesized mixed valence compounds belongs is usually one of the key questions. The issue of charge delocalization is interesting in its own right, but it is also 35 important in the context of long-range electron transfer and, possibly, for a future molecular electronics technology. When attempting to build molecular systems that can mediate charge transport over long distances, one is usually interested in materials which permit charge delocalization over many atoms, 40 and it may even be desirable to influence the extent of charge delocalization or conductivity of a given molecule by applying an external stimulus. Photoswitchable systems are particularly attractive in this respect because light can selectively and rapidly address specific molecular units. ${ }^{9}$ Mixed valence compounds with 45 molecular bridges comprised of units that can undergo reversible photoisomerization reactions are well suited, simple model systems for investigating how charge delocalization can be affected with light. The first three reports on photoswitchable mixed valence appeared in 1996 and 2000, ${ }^{10-12}$ but then this field 50 of research has been dormant until 2006, when it finally experienced a revival. ${ }^{13}$ This rents on the most significant findings from this emerging field, with particular focus on the contributions made by the groups of Launay, Akita, Nishihara, and the author's own research team.

55 The control of electron transfer by light is of long-standing interest. Recent advances in the field of photoswitchable mixed valence are highly relevant in this context, and this provided the motivation for this tutorial review. At this point, the field of photoswitchable mixed valence is yet a rather young area of ${ }_{60}$ research, and the current article provides a comprehensive review on this particular sub-discipline of electron transfer chemistry. The tutorial review begins with a section discussing the design principles for photoswitchable mixed valence compounds, introducing the most common types of photoisomerizable units 65 used for the construction of photoswitchable mixed valence systems. A subsequent section (no. 3) gives a brief introduction to two key measures for quantification of mixed valence phenomena; this section on electrochemical and optical spectroscopic measurements is kept to minimum length because 70 the theory of mixed valence chemistry has been reviewed many times before. ${ }^{1-2,4}, 14-16$ Sections $4-7$ represent the core part of the review, discussing specific case studies from the field of photoswitchable mixed-valence. A summary and conclusions 
section puts the findings from sections $4-7$ into greater context and mentions some chemical and technical challenges associated with this emerging field of research.

\section{Design principles for photoswitchable mixed 5 valence compounds}

The key feature of a photoswitchable mixed valence system is a covalent linker between two redox-active units that can be converted back and forth between two isomeric states using light as an energy input. To the best of the author's knowledge, four

10 types of photoisomerizable linkers have been used so far as bridges in photoswitchable mixed valence compounds (Scheme 1): (i) alkene linkers that can undergo E-Z isomerization; (ii) dithienylethenes which exhibit ring-closure and ring-opening reactions, (iii) norbornadiene spacers which isomerize to 15 quadricyclane units, (iv) dimethyldihydropyrene units which photoisomerize to cyclophanediene forms. In this tutorial review, a separate section will be dedicated to each of these four types of photoisomerizable units, discussing the key studies in each case.

(i)

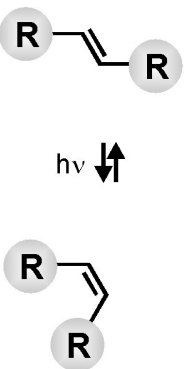

(iii)

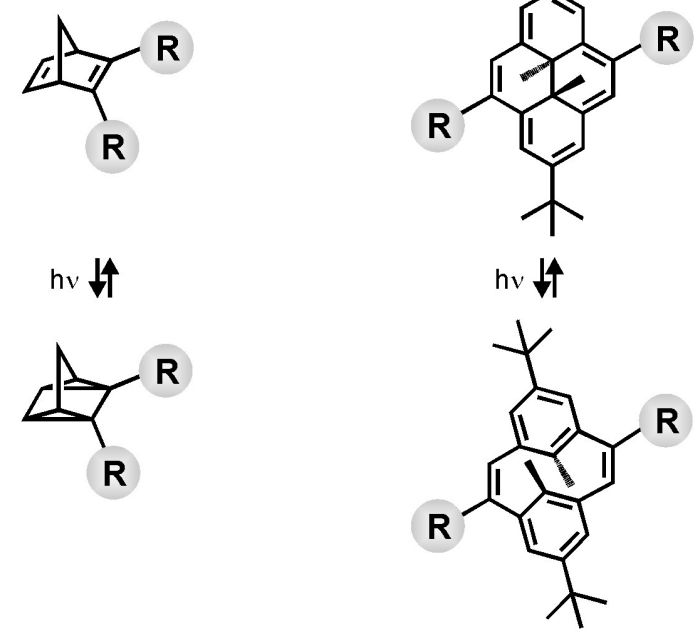

20

Scheme 1. Photoisomerizable units investigated until now in the context of photoswitchable mixed valence.

If one aims to elucidate what photoisomerizable units could potentially provide the most efficient switching functions in a molecular electronics technology, the photoswitchable unit 25 represents the most important component of a photoswitchable mixed valence system.

From this viewpoint, the choice of redox-active units is secondary. Organometallic complexes represent a popular choice because they tend to exhibit clean and reversible 30 electrochemistry, a fact that can greatly simplify the determination of comproportionation constants (section 3 ). Purely organic redox-active centers appear particularly attractive for detection of intervalence bands by optical absorption spectroscopy (section 3). A researcher's choice of redox-active 35 units may therefore be geared in large part by the experimental technique that he or she has in mind for investigation of the mixed valence phenomenon. However, even if the choice of the redox-active unit may be secondary, this does not mean at all that this choice is unimportant: There are usually clear advantages and 40 disadvantages associated with a given redox-active unit, and where appropriate, these aspects will be specifically mentioned in later sections of this article. Since this tutorial review is structured according to photoswitchable bridging units, most of the sections $4-7$ contain systems with a variety of different 45 redox-active units; no particular preference was given to certain specific redox-active moieties. The current article simply reflects what in the author's view represents the current state-of-the-art in the field of photoswitchable mixed valence.

An important aspect in mixed valence chemistry is the distance 50 dependence of electron transfer: The shorter the electron transfer distance, the more spectacular the mixed valence phenomenon is likely to manifest. ${ }^{1-2,4,14-16}$ Therefore, one usually has a strong interest in linking two redox-active moieties to the photoswitchable spacer in the closest way possible.

${ }_{55}$ Regarding design of photoswitchable mixed valence compounds, the field still has great potential for further creative development. The four photoisomerizable bridges mentioned above are by no means the only promising photoswitchable moieties that could be incorporated into mixed valence species. What is more, in several 60 instances reported below the switching functions are actually rather modest, sometimes because of a suboptimal choice of redox-active units, sometimes because the redox-active units seem to be too far apart from each other.

\section{Comproportionation constant and electronic ${ }_{65}$ coupling factor}

There are several reviews treating the theory of mixed valence in considerable depth. ${ }^{1-2,}$,, $14-16$ Here, only two aspects that are especially pertinent to the experimental case studies presented in the following sections are briefly reviewed. One important 70 experimental observable in many of the systems discussed below is the electrochemical potential for oxidation of the redox-active centers (R). In cases where cyclic voltammograms or differential pulse voltammograms exhibit a splitting $(\Delta \mathrm{E})$ between the redox waves associated with the two oxidizable units of a given 75 molecule, it is possible to calculate the equilibrium constant for the comproportionation reaction $\mathrm{R}^{\mathrm{n}+}-\mathrm{R}^{\mathrm{n}+}+\mathrm{R}^{(\mathrm{n}+1)+}-\mathrm{R}^{(\mathrm{n}+1)+} \leftrightarrows 2$ $\mathrm{R}^{\mathrm{n}+}-\mathrm{R}^{(\mathrm{n}+1)+} \cdot{ }^{3}$ The comproportionation constant $\left(\mathrm{K}_{\mathrm{c}}=10^{\Delta \mathrm{E} / 0.059 \mathrm{~V}}\right)$ is frequently used as a measure for the extent of electronic communication between the two redox-active centers of a given 80 mixed valence species. ${ }^{3}$ There can be significant electrostatic contributions to $\mathrm{K}_{\mathrm{c}},{ }^{17}$ and hence it is usually desirable to obtain complementary information on electronic communication from 
other experiments. Analysis of intervalence charge transfer (IVCT) bands by Hush theory or more elaborate three-state models is frequently the preferred method. ${ }^{15-16,18}$ The key outcome of such analyses is the electronic coupling factor $\left(\mathrm{H}_{\mathrm{AB}}\right)$ 5 which is a useful measure for the electronic interaction between the two redox-active units. ${ }^{19-21}$ Although it is the interplay between $\mathrm{H}_{\mathrm{AB}}$ and the reorganization energy $(\lambda)$ accompanying intramolecular charge transfer in a mixed valence compound that defines to which class a given system belongs, ${ }^{1,4-6,15-16}$ it may be 10 useful to note that typical $\mathrm{H}_{\mathrm{AB}}$ values are below $100 \mathrm{~cm}^{-1}$ for weakly coupled systems, between $100 \mathrm{~cm}^{-1}$ and $1000 \mathrm{~cm}^{-1}$ for systems with intermediate coupling strengths, and above 1000 $\mathrm{cm}^{-1}$ for strongly coupled systems. ${ }^{2,}{ }^{4,14} \mathrm{~K}_{\mathrm{c}}$ values range from the statistical lower limit of 4 for class I species up to values around $1510^{15}$ for class III systems. ${ }^{3}$

Both methods for characterizing mixed valence behavior mentioned here have their limitations. To name just two specific issues, calculation of $\mathrm{K}_{\mathrm{c}}$ relies on the assumption that the solvation energies of the $\mathrm{R}^{\mathrm{n}+}-\mathrm{R}^{(\mathrm{n}+1)+}$ and $\mathrm{R}^{(\mathrm{n}+1)+}-\mathrm{R}^{(\mathrm{n}+1)+}$ species are 20 the same, but this does not necessarily have to be the case. $\mathrm{H}_{\mathrm{AB}}$ is often estimated using geometrical distances between redox-active units (see below), but in some cases this is not an appropriate method. ${ }^{22}$

\section{Norbornadiene as a bridging photoswitchable 25 unit}

The first example of a photoswitchable mixed valence compound ever reported is also the one bearing most chemical resemblance to the prototype of a designed mixed valence species, the CreutzTaube ion. ${ }^{1}$ In 1996, Launay, Bignozzi and coworkers reported 30 on a molecule containing two pentaammineruthenium moieties coordinated to the cyano-groups of a central 2,3dicyanonorbornadiene unit $(1 \mathrm{n}) \cdot{ }^{10}$ Irradiation of this molecule with UV or visible light induces photoisomerization of the bridging unit from its in initial norbornadiene (n) form to the so35 called quadricyclane (q) form, resulting in molecule 1q.
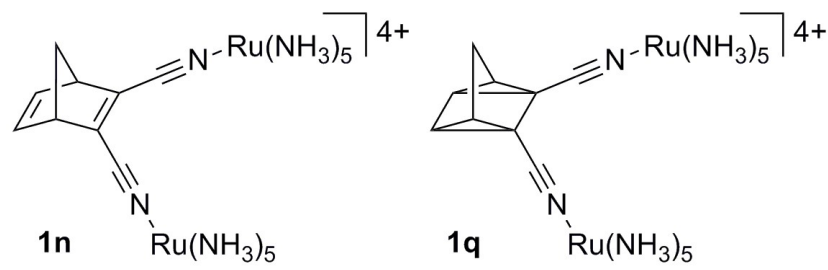

Depending on the exact excitation wavelength, photoisomerization quantum yields $(\phi)$ range from $(8.3 \pm 0.6) \cdot 10^{-4}$ to $(2.2 \pm 0.2) \cdot 10^{-2}$, with the higher values obtained for UV 40 excitation. A substantial increase of the $\mathrm{CN}$ vibrational frequency indicates that the extent of metal-nitrile back-bonding is reduced in 1q compared to $1 \mathrm{n}$, and this interpretation is consistent with the observation of a significant cathodic shift of the electrochemical potential for ruthenium(II) oxidation upon converting $1 \mathrm{n}$ to $1 \mathrm{q}$. A 45 splitting into two $\mathrm{Ru}(\mathrm{II} / \mathrm{III})$ oxidation waves, as frequently observed for strongly interacting di-ruthenium species, ${ }^{1,3}$ was not reported, and the comproportionation constant $\left(\mathrm{K}_{\mathrm{c}}\right)$ for the equilibrium $\mathrm{Ru}(\mathrm{II})-\mathrm{Ru}(\mathrm{II})+\mathrm{Ru}(\mathrm{III})-\mathrm{Ru}(\mathrm{III}) \leftrightarrows 2 \mathrm{Ru}(\mathrm{II})-\mathrm{Ru}(\mathrm{III})$ could be determined for neither of the two isomeric forms of 50 molecule 1 . However, direct evidence for metal-metal interaction in the mixed-valence form of $1 \mathrm{n}$ came from optical absorption spectroscopy: ${ }^{10} \quad$ Upon oxidizing $1 \mathrm{n}$ to $1 \mathrm{n}^{+}$with tetrabutylammonium tribromide, a weak $\left(\varepsilon<100 \mathrm{M}^{-1} \mathrm{~cm}^{-1}\right)$ and broad absorption band with a maximum near $1400 \mathrm{~nm}$ became 55 detectable. Consistent with the assignment of this near-infrared absorption to an intervalence charge transfer (IVCT) band, it disappeared again upon reducing $1 \mathrm{n}^{+}$back to $1 \mathrm{n}$ with zinc amalgam. Analysis of the IVCT band with Hush theory lead to the conclusion that the electronic coupling $\left(\mathrm{H}_{\mathrm{AB}}\right)$ between metal 60 centers amounts to $185 \mathrm{~cm}^{-1}$ in $1 \mathrm{n}^{+}$. By contrast, for $1 \mathrm{q}^{+}$no nearinfrared absorption could be detected, and it was concluded that metal-metal coupling in the quadricyclane form is insignificant.

A later study reported on similar results for a mixed valence system in which two $\mathrm{Ru}(\mathrm{bpy})_{2}(\mathrm{pp})^{2+}\left(\mathrm{bpy}=2,2^{\prime}\right.$-bipyridine; $\mathrm{pp}=$ ${ }_{65}$ 2-phenylpyridine) units are bridged by a photoisomerizable norbornadiene spacer. ${ }^{11}$

\section{Dithienylethenes as photoswitchable units}

The one-electron oxidized form of molecule 2 was the first example of a designed mixed valence compound incorporating a 70 photoswitchable dithienylethene spacer. ${ }^{11}$ As long as the dithienylethene (DTE) bridge is in its open form (2o), there is no evidence for any interaction between the two ruthenium units, but upon photoisomerization to the closed DTE form (2c), an intervalence absorption band becomes detectable.

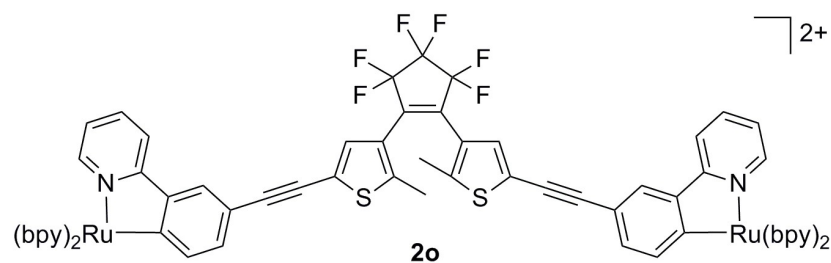

20 $2+$

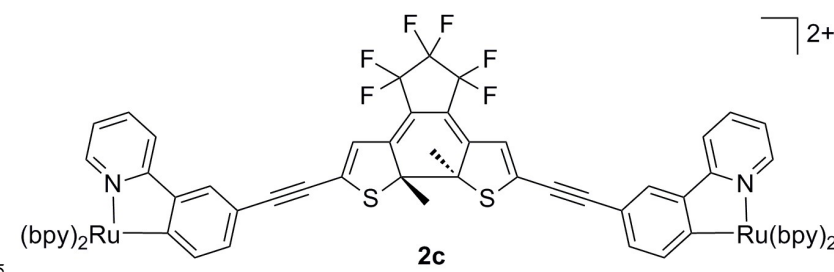

Analysis of the IVCT band with Hush theory yields $\mathrm{H}_{\mathrm{AB}}=200$ $\mathrm{cm}^{-1}$, which is a relatively high value given the large spatial separation (> $23 \AA$ ) between the two redox-active metal centers. In this context it appears appropriate to mention that the effective 80 electron transfer distance in mixed valence systems is frequently much shorter than the spatial separation between the atoms which are formally oxidized or reduced. Extended Hückel calculations yield $\mathrm{H}_{\mathrm{AB}}=170 \mathrm{~cm}^{-1}$ for $2 \mathrm{c}^{+}$and $\mathrm{H}_{\mathrm{AB}}=24 \mathrm{~cm}^{-1}$ for $2 \mathrm{o}^{+}$. Both of these calculated values are compatible with experiment and 85 suggest that electronic coupling increases by a factor of 7 upon photochemical ring closure.

Akita and coworkers explored two related systems in which ethynyl-substituents, attached at both sides of a central DTE spacer, directly coordinate to iron and ruthenium metal centers 90 (M). ${ }^{23-24}$ As additional ligands, pentamethylcyclopentadienyl $\left(\eta^{5}\right.$ $\mathrm{Cp}^{*}$ ) and a chelating 1,2-bis(diphenylphosphino)ethane (dppe) coordinate to $\mathrm{Fe}(\mathrm{II})$ or $\mathrm{Ru}(\mathrm{II})$. In the iron compound (3o), the 
metal-metal distance is $15.22 \AA$ according to X-ray crystal structure analysis.

For both systems, cyclic voltammetry provides clear evidence for an increase in the comproportionation constant upon 5 photoinduced closure of the DTE spacer (Figure 1): In the iron compound $\mathrm{K}_{\mathrm{c}}$ increases from 13 (3o) to 510 (3c), ${ }^{23}$ in the ruthenium compound from 17 (4o) to $71(4 \mathrm{c})$.
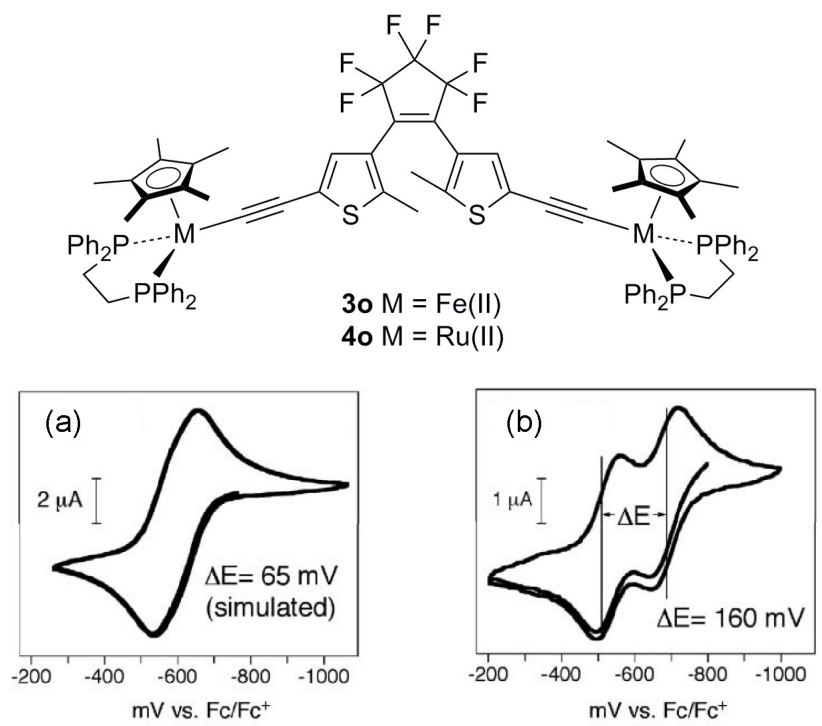

10 Figure 1. Cyclic voltammograms of molecule $3 o$ (a) and its isomer 3c (b) in $\mathrm{CH}_{2} \mathrm{Cl}_{2}$. Y. Tanaka, A. Inagaki, M. Akita, Chem. Commun. 2007, 1169-1171 - Reproduced by permission of The Royal Society of Chemistry.

The DTE-closed forms of both mixed valence species $\left(3 \mathrm{c}^{+}, 4 \mathrm{c}^{+}\right)$ 15 exhibit complicated near-infrared (NIR) absorption spectra due to the occurrence of a ligand-to-metal charge transfer (LMCT) band at $\sim 12000 \mathrm{~cm}^{-1}$ and additional NIR bands between 6000 and $10000 \mathrm{~cm}^{-1}$ which were attributed to electronic transitions occurring on the ethynyl-disubstituted DTE unit. This 20 complicated situation with several overlapping transitions permits unambiguous detection of an IVCT band exclusively in the case of the iron compound $\left(3 \mathrm{c}^{+}\right)$. Its analysis leads to a conflict which is not without precedent in the field of mixed valence: ${ }^{4}$ The lack of a significant solvent dependence of the IVCT band as well as 25 its shape point towards class III, but this seems incompatible with $\mathrm{K}_{\mathrm{c}}=510$. Consequently, $3 \mathrm{c}^{+}$was interpreted as a class II species, and in this framework $\mathrm{H}_{\mathrm{AB}}=380 \mathrm{~cm}^{-1}$ was obtained. ${ }^{24}$

Depending on how DTEs are substituted, electrochemical ringclosure or ring-opening can be induced. ${ }^{25-28}$ This type of 30 electrochromism is also observed for $4 \mathrm{o}$, giving $4 \mathrm{c}^{2+}$ as the main two-electron oxidation product. ${ }^{24}$

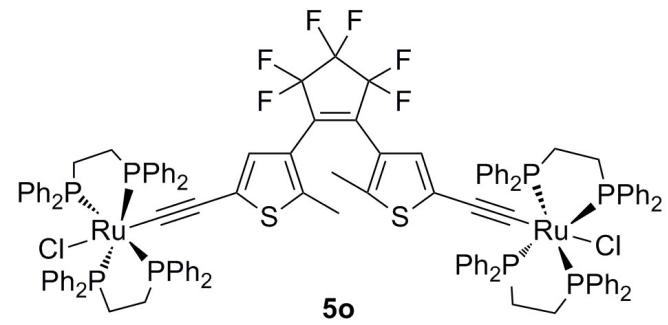

A French research group employed exactly the same ethynyl- disubstituted DTE unit as a bridging ligand between two ${ }_{35}\left[\mathrm{Cl}(\mathrm{dppe}){ }_{2} \mathrm{Ru}\right]^{+}$moieties (5o). ${ }^{29}$ As for $3 \mathrm{c}^{+}$and $4 \mathrm{c}^{+}$, the NIR absorption spectra of $5 \mathrm{c}^{+}$are complicated due a multitude of overlapping transitions. Consequently, like in the case of $4 \mathrm{c}^{+}$, an IVCT band cannot be identified unambiguously. The only evidence for an enhancement of metal-metal communication 40 upon photochemical DTE ring-closure therefore comes from cyclic voltammetry: $K_{c}$ is found to increase from a value of 28 for $5 \mathrm{o}$ to 108 for $5 \mathrm{c}$. As in the case of molecule $4 \mathrm{o}$, two-electron oxidation of 50 is accompanied by DTE ring-closure.

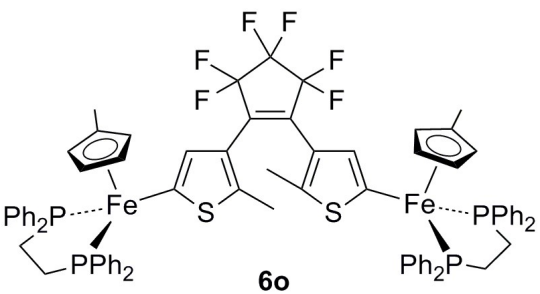

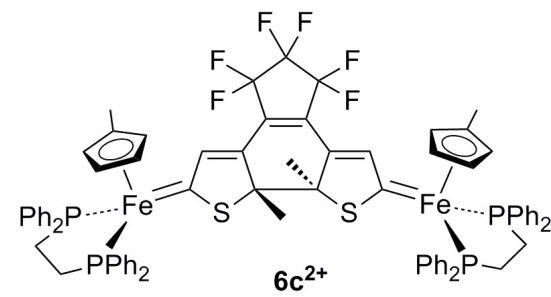

${ }_{45}$ Building on molecules $3 \mathrm{o} / 3 \mathrm{c}$ and $4 \mathrm{o} / 4 \mathrm{c}$, Akita and coworkers recently disclosed a second generation of DTE-bridged metal complexes $(60,7 \mathrm{o}, 8 \mathrm{o}, 9 \mathrm{o}, 10 \mathrm{o})$ which differ from the first generation in that the iron and ruthenium centers are now attached directly to the thiophenes of the DTE unit. ${ }^{30-31}$ This 50 shortens the metal-metal distance from $15.22 \AA$ in 30 to $10.95 \AA$ in 60 , according to crystal structure analyzes. The impact of Fe$\mathrm{Fe}$ distance shortening on switching of the metal-metal communication can be followed most directly by comparison of the nearly homologous molecules 30 and 6o: While 55 photoisomerization of $3 \mathrm{o}$ to $3 \mathrm{c}$ increases the comproportionation constant by a factor of 39 (see above), $\mathrm{K}_{\mathrm{c}}$ increases from 85 for 60 to $7.5 \cdot 10^{4}$ for $6 \mathrm{c}$.

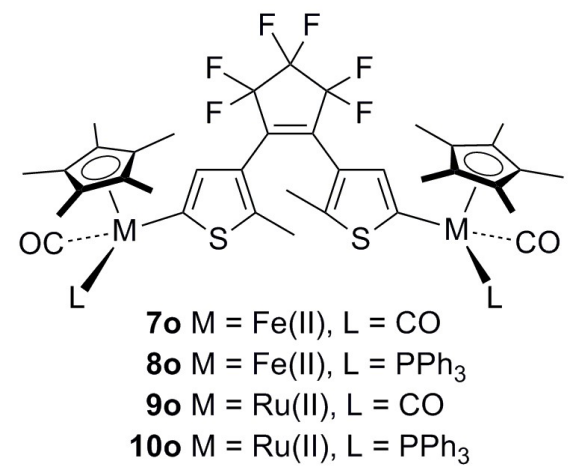

The highest switching factor (SF) between $\mathrm{K}_{\mathrm{c}}$-values for open 60 and closed isomers was found for $10 \mathrm{o} / 10 \mathrm{c}$ (5400), the lowest for $60 / 6 \mathrm{c}(880)$. The general trend is that $\mathrm{K}_{\mathrm{c}}$ increases as the ancillary ligands on $\mathrm{Fe}(\mathrm{II})$ and $\mathrm{Ru}(\mathrm{II})$ become more electron-donating (Table 1): $7 \mathrm{c}$ has two carbonyl ligands and $\mathrm{K}_{\mathrm{c}}=4.5 \cdot 10^{3}, 8 \mathrm{c}$ bears 
one carbonyl and one triphenylphosphine leading to $\mathrm{K}_{\mathrm{c}}=1.6 \cdot 10^{4}$, and $6 \mathrm{c}$ has a dppe chelating agent and $\mathrm{K}_{\mathrm{c}}=7.5 \cdot 10^{4}$. An analogous trend is observed for the ruthenium compounds $9 \mathrm{c}$ and $10 \mathrm{c}$. IVCT bands were not reported for any of the one-electron oxidized 5 forms of these molecules, hence the $\mathrm{K}_{\mathrm{c}}$-values are the only available measures of charge delocalization in these systems.

Table 1. Comproportionation constants $\left(\mathrm{K}_{\mathrm{c}}\right)$ and electronic coupling matrix elements $\left(\mathrm{H}_{\mathrm{AB}}\right)$ for the two isomers of each photoswitchable mixed valence system considered in this tutorial review.

\begin{tabular}{cccccc} 
isomer & $\mathrm{K}_{\mathrm{c}}$ & $\mathrm{H}_{\mathrm{AB}}\left[\mathrm{cm}^{-1}\right]$ & isomer & $\mathrm{K}_{\mathrm{c}}$ & $\mathrm{H}_{\mathrm{AB}}\left[\mathrm{cm}^{-1}\right]$ \\
\hline $1 \mathrm{n}$ & & & $1 \mathrm{q}$ & & $185^{\mathrm{a}}$ \\
$2 \mathrm{o}$ & & $24^{\mathrm{b}}$ & $2 \mathrm{c}$ & $12^{\mathrm{d}}$ & $200^{\mathrm{d}}$ \\
$3 \mathrm{o}$ & $13^{\mathrm{c}}$ & & $3 \mathrm{c}$ & $510^{\mathrm{c}}$ & 380 \\
$4 \mathrm{o}$ & $17^{\mathrm{c}}$ & & $4 \mathrm{c}$ & $71^{\mathrm{c}}$ & \\
$5 \mathrm{o}$ & $28^{\mathrm{c}}$ & & $5 \mathrm{c}$ & $108^{\mathrm{c}}$ & \\
$6 \mathrm{o}$ & $85^{\mathrm{c}}$ & $6 \mathrm{c}$ & $7.5 \cdot 10^{4 \mathrm{c}}$ & \\
$7 \mathrm{o}$ & $\sim 4^{\mathrm{c}}$ & & $7 \mathrm{c}$ & $4.5 \cdot 10^{3 \mathrm{c}}$ & \\
$8 \mathrm{o}$ & $\sim 4^{\mathrm{c}}$ & & $8 \mathrm{c}$ & $1.6 \cdot 10^{4 \mathrm{c}}$ & \\
$9 \mathrm{o}$ & $6.2^{\mathrm{c}}$ & & $\mathrm{c}$ & $7.2 \cdot 10^{3 \mathrm{c}}$ & \\
$10 \mathrm{o}$ & $\sim 4^{\mathrm{c}}$ & & $10 \mathrm{c}$ & $2.2 \cdot 10^{4 \mathrm{c}}$ & \\
$11 \mathrm{o}$ & & & $11 \mathrm{c}$ & $349^{\mathrm{c}}$ & \\
$12 \mathrm{o}$ & $<25^{\mathrm{d}}$ & & $12 \mathrm{c}$ & $7.9^{3} \cdot 10^{3 \mathrm{~d}}$ & $5550^{\mathrm{d}}$ \\
$13 \mathrm{o}$ & $<25^{\mathrm{d}}$ & & $13 \mathrm{c}$ & $349^{\mathrm{d}}$ & $599^{\mathrm{d}, \mathrm{e}}$ \\
E-14 & $15^{\mathrm{c}}$ & & $\mathrm{Z}-14$ & $7^{\mathrm{c}}$ & \\
E-15 & $18^{\mathrm{c}}$ & $534^{\mathrm{c}}$ & $\mathrm{Z}-15$ & $12^{\mathrm{c}}$ & $529^{\mathrm{c}}$ \\
$16_{\text {DHP }}$ & $57^{\mathrm{f}}$ & & $16_{\mathrm{CPD}}$ & $\sim 4^{\mathrm{f}}$ &
\end{tabular}

$10{ }^{\mathrm{a}} \mathrm{In} \mathrm{CD}_{3} \mathrm{OD} .{ }^{\mathrm{b}}$ Calculated based on extended Hückel theory, see text. ${ }^{\mathrm{c}}$ In $\mathrm{CH}_{2} \mathrm{Cl}_{2} .{ }^{\mathrm{d}}$ In $\mathrm{CH}_{3} \mathrm{CN}$. ${ }^{\mathrm{e}}$ Average value of the upper and lower limit mentioned in the text. ${ }^{\mathrm{f}}$ In 1,3-dichloropropane.

There are remarkable differences in photoisomerization efficiencies between the iron and ruthenium molecules $6-10 .^{31}$

${ }_{15}$ When irradiating THF solutions of the iron compounds 60 and 80 at wavelengths shorter than $360 \mathrm{~nm}$ there is essentially no photoisomerization, while for the iron compound $7 \mathrm{o}$ a photostationary state containing only $17 \%$ of $7 \mathrm{c}$ can be attained. By contrast, under identical experimental conditions the 20 ruthenium compounds evolve to photostationary states containing $73 \%$ of $9 \mathrm{c}$ and $92 \%$ of $10 \mathrm{c}$. Analysis with time-dependent density functional theory suggested that in the ruthenium systems the lowest triplet excited state is DTE-localized. ${ }^{31}$ Thus, initial singlet-singlet photoexcitation is ensued by intersystem crossing 25 promoted by the metal, and this can be followed by energy transfer to the lowest triplet excited state of DTE from where ring-closure is known to be efficient. In the iron compounds the lowest triplet excited state is metal-localized, hence after intersystem crossing the excitation energy dissipates on the metal ${ }^{30}$ center, ${ }^{32}$ and the DTE triplet state is not populated. ${ }^{31}$

Molecules $6-10$ exhibit ring-closure upon two-electron oxidation, and this process seems to be even more efficient than in the case of the DTE-systems with ethynyl linkers (3o and 4o). For the dications $6 c^{2+}-10 c^{2+}$ it is possible to draw resonance ${ }_{35}$ structures in which there is a formal metal-carbon double bond, ${ }^{31}$ and this may help understanding why electrochemical ringclosure proceeds with relative ease in these compounds. Direct evidence for the double bond character of the $\mathrm{Fe}-\mathrm{C}$ bond in $8 \mathrm{c}^{2+}$ comes from X-ray crystal structure analysis. In $8 \mathrm{c}^{2+}$ the two

40 determined Fe-C distances are 1.852(5) $\AA$ and 1.871(6) $\AA$, while in the neutral molecule $8 \mathrm{o}$ an Fe-C distance of 1.979(4) $\AA$ was found. ${ }^{30}$
Starting from the twofold ethynyl-substituted DTE bridge employed in molecules 3o, 4o, and 5o, Liu and coworkers 45 synthesized a DTE linker with two pendant vinyl groups that can ligate to ruthenium centers. ${ }^{33} \mathrm{~A}$ series of four ruthenium complexes with different ancillary ligands was investigated, all of which show similar photophysical and electrochemical properties. Molecule 11o is a representative example. For its ${ }_{50}$ isomer $11 \mathrm{c} \mathrm{K}_{\mathrm{c}}=349$ was determined, whereas the cyclic voltammogram of 110 exhibits no noticeable splitting of the relevant redox waves, hence $\mathrm{K}_{\mathrm{c}}$ is presumably $<25$ in this case. Replacement of the hexafluoropentene backbone in the DTE by an ordinary cyclopentene unit had no significant impact on the 55 comproportionation constants, and IVCT bands were not reported..$^{33}$

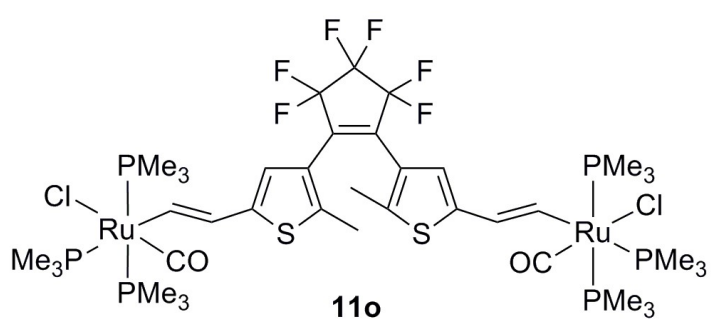

Although frequently associated with coordination compounds and organometallic complexes, the phenomenon of mixed 60 valence is very common in purely organic substances. ${ }^{5-6,60}$ Building on the numerous studies of mixed valence in bis(triarylamine) radical cations, ${ }^{6,34-35}$ the DTE-bridged systems $12 \mathrm{o} / 12 \mathrm{c}$ and $13 \mathrm{o} / 13 \mathrm{c}$ were investigated in the context of photoswitchable mixed valence. ${ }^{22}$ Both of these compounds ${ }_{65}$ contain redox-active tertiary amino-groups. In the case of $12 \mathrm{o} / 12 \mathrm{c}$ the nitrogen atoms are attached directly to the thiophene rings, while in molecules $13 \mathrm{o} / 13 \mathrm{c}$ there are $p$-xylene spacers between the $\mathrm{N}$-atoms and the thiophenes. The estimated throughbond N-N distances are $9.3 \AA$ for $12 \mathrm{c}$ and $17.6 \AA$ for $13 \mathrm{c}$.<smiles>COc1ccc(N(c2ccc(OC)cc2)c2cc(C3=C(c4cc(N(c5ccc(OC)cc5)c5ccc(OC)cc5)sc4C)C(F)(F)C(F)(F)C3(F)F)c(C)s2)cc1</smiles><smiles>COc1ccc(N(c2ccc(OC)cc2)c2cc(C)c(-c3cc(C4=C(c5cc(-c6cc(C)c(N(c7ccc(OC)cc7)c7ccc(OC)cc7)cc6C)sc5C)C(F)(F)C(F)(F)C4(F)F)c(C)s3)cc2C)cc1</smiles>

Figure $2 \mathrm{a}$ shows that in molecule $13 \mathrm{c}$ the redox waves 
associated with one-electron oxidation of the two triarylamine units are separated by $150 \mathrm{mV}$. Figure $2 \mathrm{~b}$ exhibits an analogous cyclic voltammogram for molecule $12 \mathrm{c}$, but in this case the respective potential splitting $(\Delta \mathrm{E})$ is $230 \mathrm{mV}$. These $\Delta \mathrm{E}$-values 5 yield comproportionation constants of 349 for molecule $13 \mathrm{c}$ and $7.9 \cdot 10^{3}$ for $12 \mathrm{c} .22$ For the open isomers of both molecules (12o, $13 \mathrm{o}) \mathrm{K}_{\mathrm{c}}$ is estimated to be $<25$ due to lack of any noticeable splitting between triarylamine-based one-electron oxidations in cyclic voltammetry.
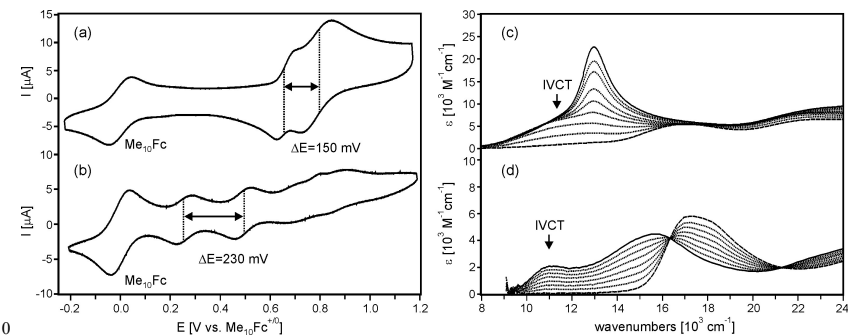

Figure 2. Cyclic voltammograms of molecule 13c (a) and molecule 12c (b) in $\mathrm{CH}_{3} \mathrm{CN}$. Changes in optical absorption of $\mathrm{CH}_{3} \mathrm{CN}$ solutions of molecule $13 \mathrm{c}$ (c) and molecule 12c (d) following addition of $\mathrm{Cu}\left(\mathrm{ClO}_{4}\right)_{2}$ oxidant. The dashed lines show the initial spectra, the solid lines are 15 the final spectra obtained after addition of 1 eq. of $\mathrm{Cu}\left(\mathrm{ClO}_{4}\right)_{2}$. B. He, O S. Wenger, J. Am. Chem. Soc. 2011, 133, 17027-17036. Copyright 2011 American Chemical Society.

Titration of acetonitrile solutions of the open and closed forms of molecules 12 and 13 with copper(II) perchlorate permits 20 systematic investigation of the oxidation sequence from neutral $12 / 13$ molecules to $12^{+} / 13^{+}$monocations and, finally, to $12^{2+} / 13^{2+}$ dications. For the closed forms of the monocations $\left(12 \mathrm{c}^{+}, 13 \mathrm{c}^{+}\right)$ near-infrared absorptions appear (Figure $2 \mathrm{c} / 2 \mathrm{~d}$ ) and some of them can be identified as IVCT bands. In the case of $13 \mathrm{c}^{+}$(Figure $2 \mathrm{c}$ ), 25 the IVCT band shows up as a broad and relatively weak feature centered around $11250 \mathrm{~cm}^{-1}$ which is somewhat hidden below a more intense, triarylamine-based absorption maximizing at 12900 $\mathrm{cm}^{-1}$. Analysis of the IVCT band in the framework of Hush theory yields $\mathrm{H}_{\mathrm{AB}}=476 \mathrm{~cm}^{-1}$ when taking the geometrical N-N 30 distance $\left(\mathrm{d}_{\mathrm{NN}}\right)$ of $17.6 \AA$ as an effective electron transfer distance $\left(\mathrm{d}_{\mathrm{AB}}\right)$. However, prior work on bis(triarylamine) radical monocations demonstrated that $\mathrm{d}_{\mathrm{AB}}$ is frequently only roughly two thirds of $d_{N N}$ in mixed valence systems of this type. ${ }^{5,6,60}$ On the basis of $\mathrm{d}_{\mathrm{AB}}=2 / 3 \cdot 17.6 \AA$ one obtains $\mathrm{H}_{\mathrm{AB}}=722 \mathrm{~cm}^{-1}$. It 35 appears reasonable to consider the values of $476 \mathrm{~cm}^{-1}$ and 722 $\mathrm{cm}^{-1}$ as lower and upper limits of $\mathrm{H}_{\mathrm{AB}}$ in $13 \mathrm{c}^{+} .22$

In the case of $12 \mathrm{c}^{+}$(Figure 2d), an absorption centered at $11100 \mathrm{~cm}^{-1}$ was identified as an IVCT band. Due to its solvent independence and narrow width, this band was analyzed in the 40 framework of class III mixed valence. This approach yields $\mathrm{H}_{\mathrm{AB}}$ $=5550 \mathrm{~cm}^{-1}$, a value close to those obtained for four chemically related bis(triarylamine) mixed valence systems with nonphotoswitchable bithiophene bridges and comparable N-N distances. ${ }^{59}$ No IVCT bands can be observed for the open forms $4512 \mathrm{o}^{+}$and $13 \mathrm{o}^{+}$.

The conclusion from this work on bis(triarylamine) systems is that photoisomerization of the DTE linker from the open to the closed form induces a changeover from class I mixed valence behavior to class II in the case of $13 \mathrm{c}^{+}$and to class III in the case 50 of $12 \mathrm{c}^{+} .22$

\section{Photoswitching based on $\mathrm{E}-\mathrm{Z}$ isomerism in diethynylethenes}

E-Z photoisomerization reactions have been explored to considerable extent in stilbene and azobenzene derivatives. Initial 55 efforts to analyze the mixed-valence interaction in cisazoferrocene in a quantitative manner were not successful, ${ }^{36}$ and therefore Nishihara and coworkers turned their attention to photoinduced E-Z isomerization in diethynylethene systems with attached ferrocene or triarylamine units as redox-active centers. ${ }^{37}$ ${ }_{60}^{38}$ Irradiation of molecule E-14 in dichloromethane with yellow $(578 \mathrm{~nm})$ or green $(546 \mathrm{~nm})$ light leads to a photostationary state comprised of $89 \%$ Z-14 and $11 \%$ E- 14 .

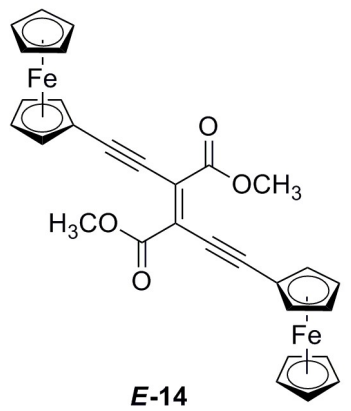

Both isomers exhibit an intense absorption band in the visible ${ }_{65}$ spectral range which is assigned to a charge transfer transition from ferrocene d-orbitals to ethynylethene $\pi^{*}$ orbitals, i. e., in a sense it is an MLCT band. IVCT absorptions could not be detected, and consequently the only experimental evidence for changes in ferrocene-ferrocene interaction upon 70 photoisomerization comes from electrochemistry. Indeed, the cyclic voltammograms of E-14 and Z-14 are slightly different, and Nishihara and coworkers extracted potential splittings $(\Delta \mathrm{E})$ of $70 \mathrm{mV}$ (E-14) and $48 \mathrm{mV}$ (Z-14) from these data. ${ }^{37}$ These $\Delta \mathrm{E}$ values translate to comproportionation constants of 15 (E-14) and 757 (Z-14). The higher $\mathrm{K}_{\mathrm{c}}$ value in the E-form is consistent with the expectation of weaker $\pi$-conjugation in the $Z$-isomer. This experimental finding also indicates that direct (through-space) interaction between the two ferrocene units in Z-14 over the (crystallographically determined) $\mathrm{Fe}-\mathrm{Fe}$ distance of $6.17 \AA$ is 80 insignificant.

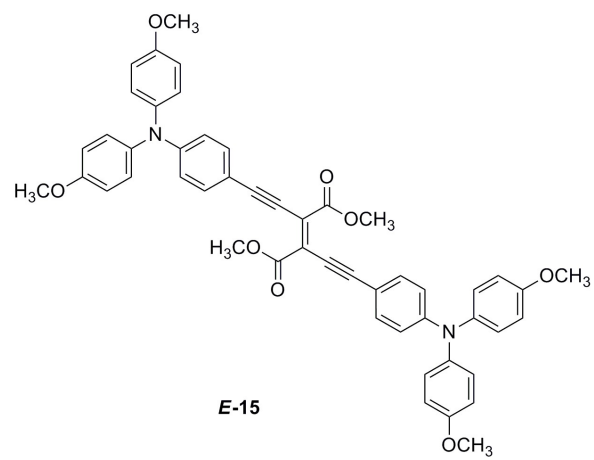

Molecule 15 represents an all-organic counterpart to molecule 14. In several respects, the triarylamine-based system 15 exhibits more favorable properties for investigation of photoswitchable 85 mixed valence than the ferrocene-based molecule $14: 38$ (i) The 
quantum yield for E-Z photoisomerization is more than 3 orders of magnitude higher for the organic system because it has no energetically low lying metal-based (triplet) states through which the excitation energy can dissipate rather than being used for 5 photoisomerization; (ii) an IVCT band can be detected for $15^{+}$but not for $14^{+}$; (iii) redox potential splittings in cyclic voltammetry are somewhat larger in the all-organic compound. Unfortunately, the differences between E-15 and Z-15 are minor, both regarding $\mathrm{K}_{\mathrm{c}}$ and $\mathrm{H}_{\mathrm{AB}}$ : The comproportionation constant decreases from a 10 value of 18 for $E-15$ to a value of 12 for $Z-15$, while $H_{A B}$ changes from $534 \mathrm{~cm}^{-1}$ for the E-isomer to $529 \mathrm{~cm}^{-1}$ in the Z-isomer. ${ }^{38}$ Given the large uncertainties in $\mathrm{d}_{\mathrm{AB}}$ (see above), the variations in $\mathrm{H}_{\mathrm{AB}}$ between $\mathrm{E}$ - and Z-forms reported here are insignificant. In conclusion, the diethynylethene systems investigated so far 15 provide much less spectacular evidence for photoswitchable mixed valence than the DTE- or norbornadiene-based systems presented in the prior sections.

\section{Dimethyldihydropyrene as a photoswitchable spacer}

20 Aside from the norbornadiene/quadricyclane study from section 3 (1n, 1q), the most exotic example of a photoswitchable mixed valence system investigated so far is Nishihara's ferrocenedisubstituted dimethyldihydropyrene molecule 16 DHP. ${ }^{39}$ When irradiating a THF solution of 16DHP with yellow $(578 \mathrm{~nm})$ light, 25 the dimethyldihydropyrene (DHP) core of the molecule is excited into a $\pi-\pi *$ transition. This is followed by isomerization of the DHP moiety into a cyclophanediene (CPD) form (16 CPD). Continued irradiation at $578 \mathrm{~nm}$ ultimately results in a photostationary state containing $97 \%$ of $16 \mathrm{CPD}$ and $3 \%$ of $16 \mathrm{DHP}$, 30 as determined by ${ }^{1} \mathrm{H}$ NMR spectroscopy. The CPD form is significantly less $\pi$-conjugated than the DHP isomer, consequently one might expect stronger ferrocene-ferrocene interaction in $16_{\mathrm{DHP}}$ than in $16_{\mathrm{CPD}}$. Indeed, the cyclic voltammogram of $16 \mathrm{DHP}$ in 1,3-dichloropropane exhibits a

35 noticeable splitting between the waves associated with oneelectron oxidation of the two ferrocene units, leading to a comproportionation constant of 57 for $16 \mathrm{DHP} .{ }^{39} \mathrm{By}$ contrast, there is no evidence for separation of the respective oxidation waves in $16_{\mathrm{CPD}}$, hence $\mathrm{K}_{\mathrm{c}}$ is assumed to be close to the statistical value of 40 . IVCT bands were not reported.

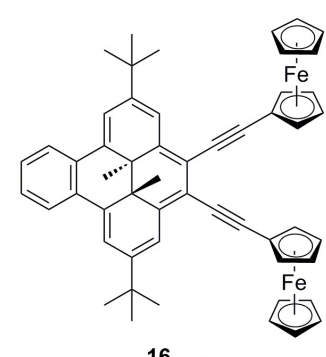

$16_{\text {DHP }}$

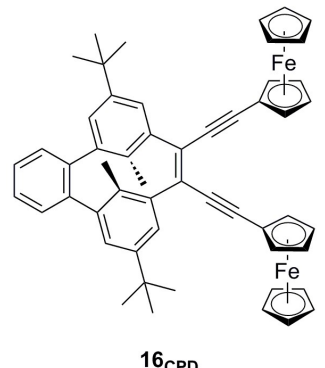

$16_{\mathrm{CPD}}$

\section{Summary and conclusions}

Among the four types of photoisomerizable units investigated so far in the context of photoswitchable mixed valence, ${ }_{45}$ dithienylethenes (DTEs) lead by far to the most pronounced switching properties. The two most spectacular cases reported to date include molecule 10 in which DTE ring closure increases $\mathrm{K}_{\mathrm{c}}$ by a factor of $5400,,^{30-31}$ and molecule 12 in which photocyclization of the DTE spacer induces a changeover from 50 class I to class III mixed valence behavior with $\mathrm{H}_{\mathrm{AB}}$ on the order of $5550 \mathrm{~cm}^{-1}$ for $12 \mathrm{c}^{+} .22$

Until now, ferrocene or related organometallic (Fe(II) or $\mathrm{Ru}(\mathrm{II})$ ) complexes have been used very frequently as redox-active units in the field of photoswitchable mixed valence. ${ }^{13,} 23-24,30-31,33$, ${ }_{55}{ }^{37-41}$ An advantage of these systems is their clean electrochemistry and hence relatively facile determination of comproportionation constants. The disadvantage is that $\mathrm{K}_{\mathrm{c}}$-values are often the only experimentally accessible measure of electronic interaction between such redox centers because IVCT bands usually remain 60 unobserved. Purely organic mixed valence systems represent an attractive alternative in this respect: Selected triarylamines exhibit very clean electrochemistry while at the same time can give rise to fairly intense IVCT absorptions. Purely organic mixed valence systems offer the additional advantage that there

${ }_{65}$ are usually no energetically low-lying triplet excited states on the redox-active centers that can negatively affect the quantum yield for photoisomerization of the bridging unit. ${ }^{32,42-43}$

Experimental investigations of electronic communication between redox-active units bridged by a photoisomerizable 70 bridge are so far mostly limited to electrochemical studies (cyclic voltammetry, differential pulse voltammetry) and optical absorption spectroscopy. EPR spectroscopy would appear to be a promising additional tool, particularly in view of recent investigations of mixed valence phenomena in organic systems. ${ }^{4-}$ ${ }_{75} 45,59$

The general concept of investigating electronic communication mediated by a photoswitchable molecular unit through exploring mixed valence phenomena is clearly a very successful approach. When attempting to explore photoinduced electron transfer in 80 donor-bridge-acceptor compounds containing a photoisomerizable bridge, one is often confronted with the problem that the photoexcitation required to trigger the charge transfer event can also induce photoisomerization. ${ }^{42-43,}$,6-49 This undesired situation may arise either through direct excitation of ${ }_{85}$ the isomerizable bridge or via energy transfer from the donor (or the acceptor) to the bridge. ${ }^{32,42-43,46-49}$ Since IVCT bands usually occur in the NIR spectral range while shorter wavelengths are required for bridge photoisomerization, this problem is much less prone to occur in mixed valence compounds.

90 While there is considerable room for improvement of the mixed valence properties of photoswitchable systems, it seems clear that much future work will be geared at direct measurement of the conductance of photoisomerizable molecules. Although the scope of this tutorial review is limited to photoswitchable mixed 95 valence, it appears appropriate to mention in this context that there have already been several investigations of light-induced conductance switching. ${ }^{50-58}$ To name just one specific example, the direct measurement of the resistance of the two isomers of a DTE molecule incorporated into a break junction circuit yielded $100526 \pm 90 \mathrm{M} \Omega$ for the open form and $4 \pm 1 \mathrm{M} \Omega$ for the closed isomer. ${ }^{50}$ The switching factor of 132 is in line with the switching factors determined for some of the mixed valence systems discussed above.

With some broad-mindedness, photoswitchable mixed valence 
may be considered as a form of light-controlled conductance switching. It is likely that future investigations of photoswitchable mixed valence will continue to provide information on charge transfer phenomena that is complementary 5 to the results obtained from studies of light-controlled conductance switching in molecules which are integrated in real electronic circuits.

\section{Notes and references}

${ }^{a}$ Georg-August-Universität Göttingen, Institut für Anorganische Chemie, 10 Tammannstrasse 4, D-37077 Göttingen, Germany. Fax: +49 (0)551 39 3373; Tel: +49(0)551 39 19424; E-mail: oliver.wenger@chemie.unigoettingen.de

1. C. Creutz, Prog. Inorg. Chem., 1983, 30, 1.

15 2. D. M. D'Alessandro and F. R. Keene, Chem. Rev., 2006, 106, 2270.

3. W. Kaim, A. Klein and M. Glöckle, Acc. Chem. Res., 2000, 33, 755.

4. K. D. Demadis, C. M. Hartshorn and T. J. Meyer, Chem. Rev., 2001, 101, 2655.

5. S. F. Nelsen, Chem. Eur. J., 2000, 6, 581.

20 6. J. Hankache and O. S. Wenger, Chem. Rev., 2011, 111, 5138.

7. A. F. Heyduk and D. G. Nocera, Science, 2001, 293, 1639.

8. M. B. Robin and P. Day, Adv. Inorg. Chem. Radiochem., 1967, 10, 247.

9. B. L. Feringa, Molecular Switches, Wiley-VCH, Weinheim, 2001.

25 10. P. Lainé, V. Marvaud, A. Gourdon, J.-P. Launay, R. Argazzi and C. A. Bignozzi, Inorg. Chem., 1996, 35, 711.

11. S. Fraysse, C. Coudret and J.-P. Launay, Eur. J. Inorg. Chem., 2000, 1581.

12. J.-P. Launay, S. Fraysse and C. Coudret, Mol. Cryst. Liquid Cryst., 2000, 344, 125.

13. M. Akita, Organometallics, 2011, 30, 43.

14. D. M. D'Alessandro and F. R. Keene, Chem. Soc. Rev., 2006, 35, 424 .

15. B. S. Brunschwig, C. Creutz and N. Sutin, Chem. Soc. Rev., 2002, 31, 168 .

16. B. S. Brunschwig and N. Sutin, Coord. Chem. Rev., 1999, 187, 233.

17. D. M. D'Alessandro and F. R. Keene, Dalton Trans., 2004, 3950.

18. N. S. Hush, Coord. Chem. Rev., 1985, 64, 135.

19. H. M. McConnell, J. Chem. Phys., 1961, 35, 508

40 20. C. P. Hsu, Acc. Chem. Res., 2009, 42, 509.

21. O. S. Wenger, Acc. Chem. Res., 2011, 44, 25.

22. B. He and O. S. Wenger, J. Am. Chem. Soc., 2011, 133, 17027.

23. Y. Tanaka, A. Inagaki and M. Akita, Chem. Commun., 2007, 1169.

24. Y. Tanaka, T. Ishisaka, A. Inagaki, T. Koike, C. Lapinte and M. $45 \quad$ Akita, Chem. Eur. J., 2010, 16, 4762.

25. A. Peters and N. R. Branda, Chem. Commun., 2003, 954.

26. A. Peters and N. R. Branda, J. Am. Chem. Soc., 2003, 125, 3404.

27. W. R. Browne, J. J. D. de Jong, T. Kudernac, M. Walko, L. N. Lucas, K. Uchida, J. H. van Esch and B. L. Feringa, Chem. Eur. J., 2005, 11, 6414.

28. W. R. Browne, J. J. D. de Jong, T. Kudernac, M. Walko, L. N. Lucas, K. Uchida, J. H. van Esch and B. L. Feringa, Chem. Eur. J., 2005, 11, 6430 .

29. Y. F. Liu, C. Lagrost, K. Costuas, N. Tchouar, H. Le Bozec and S. Rigaut, Chem. Commun., 2008, 6117.

30. K. Motoyama, T. Koike and M. Akita, Chem. Commun., 2008, 5812.

31. K. Motoyama, H. F. Li, T. Koike, M. Hatakeyama, S. Yokojima, S. Nakamura and M. Akita, Dalton Trans., 2011, 40, 10643.

32. R. T. F. Jukes, V. Adamo, F. Hartl, P. Belser and L. De Cola, Inorg. Chem., 2004, 43, 2779.

33. Y. Lin, J. J. Yuan, M. Hu, J. Cheng, J. Yin, S. Jin and S. H. Liu, Organometallics, 2009, 28, 6402 .

34. C. Lambert and G. Nöll, J. Am. Chem. Soc., 1999, 121, 8434.

35. V. Coropceanu, M. Malagoli, J. M. André and J. L. Brédas, J. Am. Chem. Soc., 2002, 124, 10519.

36. M. Kurihara, T. Matsuda, A. Hirooka, T. Yutaka and H. Nishihara, J. Am. Chem. Soc., 2000, 122, 12373.
37. R. Sakamoto, M. Murata and H. Nishihara, Angew. Chem. Int. Ed., 2006, 45, 4793.

70 38. R. Sakamoto, S. Kume and H. Nishihara, Chem. Eur. J., 2008, 14 6978.

39. S. Muratsugu, S. Kume and H. Nishihara, J. Am. Chem. Soc., 2008 , 130, 7204.

40. S. Kume and H. Nishihara, Dalton Trans., 2008, 3260.

75 41. M. Akita and T. Koike, Dalton Trans., 2008, 3523.

42. J. M. Endtner, F. Effenberger, A. Hartschuh and H. Port, J. Am. Chem. Soc., 2000, 122, 3037.

43. P. Belser, L. De Cola, F. Hartl, V. Adamo, B. Bozic, Y. Chriqui, V. M. Iyer, R. T. F. Jukes, J. Kuhni, M. Querol, S. Roma and N. Salluce, Adv. Funct. Mater., 2006, 16, 195.

44. D. R. Kattnig, B. Mladenova, G. Grampp, C. Kaiser, A. Heckmann and C. Lambert, J. Phys. Chem. C, 2009, 113, 2983.

45. V. Lloveras, J. Vidal-Gancedo, T. M. Figueira-Duarte, J. F. Nierengarten, J. J. Novoa, F. Mota, N. Ventosa, C. Rovira and J. Veciana, J. Am. Chem. Soc., 2011, 133, 5818.

46. M. N. Roberts, J. K. Nagle, J. G. Finden, N. R. Branda and M. O. Wolf, Inorg. Chem., 2009, 48, 19.

47. J. Kärnbratt, M. Hammarson, S. M. Li, H. L. Anderson, B. Albinsson and J. Andréasson, Angew. Chem. Int. Ed., 2010, 49, 1854.

90 48. O. S. Wenger, L. M. Henling, M. W. Day, J. R. Winkler and H. B. Gray, Polyhedron, 2004, 23, 2955.

49. F. M. Raymo and M. Tomasulo, Chem. Soc. Rev., 2005, 34, 327

50. J. He, F. Chen, P. A. Liddell, J. Andreasson, S. D. Straight, D. Gust, T. A. Moore, A. L. Moore, J. Li, O. F. Sankey and S. M. Lindsay, Nanotechnology, 2005, 16, 695.

51. S. J. van der Molen, J. H. Liao, T. Kudernac, J. S. Agustsson, L. Bernard, M. Calame, B. J. van Wees, B. L. Feringa and C. Schönenberger, Nano Lett., 2009, 9, 76.

52. A. C. Whalley, M. L. Steigerwald, X. Guo and C. Nuckolls, J. Am. Chem. Soc., 2007, 129, 12590.

53. K. Uchida, Y. Yamanoi, T. Yonezawa and H. Nishihara, J. Am. Chem. Soc., 2011, 133, 9239.

54. W. R. Browne and B. L. Feringa, Chimia, 2010, 64, 398-403.

55. J. M. Mativetsky, G. Pace, M. Elbing, M. A. Rampi, M. Mayor and P. Samori, J. Am. Chem. Soc., 2008, 130, 9192.

56. N. Weibel, S. Grunder and M. Mayor, Org. Biomol. Chem., 2007, 5, 2343-2353.

57. N. Katsonis, T. Kudernac, M. Walko, S. J. van der Molen, B. J. van Wees and B. L. Feringa, Adv. Mater., 2006, 18, 1397.

110 58. M. Ikeda, N. Tanifuji, H. Yamaguchi, M. Irie and K. Matsuda, Chem. Commun., 2007, 1355.

59. A. Rosspeintner, M. Griesser, I. Matsumoto, Y. Teki, G. Li, S. F. Nelsen and G. Gescheidt, J. Phys. Chem. A. 2010, 114, 6487.

60. A. Heckmann and C. Lambert, Angew. Chem. Int. Ed. 2012, 51, 326. 115 